\title{
Applications of intelligent \& fuzzy theory in engineering technologies and applied science
}

\author{
Álvaro Rocha* \\ Department of Informatics Engineering, University of Coimbra, Coimbra, Portugal
}

The field "Intelligent \& Fuzzy Theory" has been expanding its topic and boundary in the past decades in order to reflect the complex requirements of the information society. Consequently, many academic studies have tried to address the complex information science and technology issues in wider perspectives.

Thus, this special issue has a set of selected extended articles of the 4th World Conference on Information Systems and Technologies held at Recife, PE, Brazil, 22 - 24 March 2016, which aims to more deep insights about the development of "Applications of Intelligent \& Fuzzy Theory in Engineering Technologies and Applied Science".

This edition is the continuation of our publishing activities, all the included contents were anonymously reviewed by distinguished experts to maintain academic excellence and integrity. We assure our readers that Journal of Intelligent \& Fuzzy Systems will serve as a key exchange platform for publications in Intelligent \& Fuzzy Theory field. The authors and readers can count on the journal.

*Corresponding author. Álvaro Rocha, Department of Informatics Engineering, University of Coimbra, Coimbra, Portugal. Tel.: +351 961539027; E-mail: amrocha@dei.uc.pt. 